\title{
Doenças crônicas e trajetórias assistenciais: avaliação do sistema de saúde de pequenos municípios*
}

\author{
I ${ }^{1}$ Luciane Marques Raupp, ${ }^{2}$ Gisele Dhein, ${ }^{3}$ Cássia Regina Gotler Medeiros, \\ ${ }^{4}$ Magali Teresinha Quevedo Grave, ${ }^{5}$ Olinda Maria de Fátima Lechmann Saldanha, \\ ${ }^{6}$ Marilucia Vieira dos Santos, 7 Lydia Christman Espindola Koetz, \\ ${ }^{8}$ Gizele Pires de Oliveira Almerom I
}

Abstract: Este trabalho apresenta os resultados da análise qualitativa de um estudo que visou identificar e avaliar a atenção às condições crônicas mais prevalentes na região

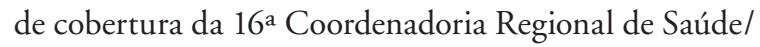
RS. Foram realizadas entrevistas semiestruturadas com 12 pessoas com Doenças Crônicas Não Transmissíveis (DCNT), descrevendo suas trajetórias assistenciais. Foram contatados os serviços de atenção básica $(\mathrm{AB})$ de seis municípios. Os participantes foram selecionados segundo critérios populacionais e de cobertura de Estratégia de Saúde da Família (ESF). As entrevistas foram analisadas pelo método de Análise de Conteúdo (BARDIN, 2012), através de duas categorias. Na primeira, "Acesso ao sistema de saúde”, foram abordados temas relativos às formas de entrada dos usuários no sistema e suas trajetórias assistenciais, dificuldades de acesso à atenção em saúde e a transporte, urgência e medicações. Na segunda categoria, "A satisfação dos usuários com os serviços de saúde", foram incluídos dados relacionados à percepção da atenção prestada na $\mathrm{AB}$, à avaliação da atenção recebida e ao tempo entre diagnóstico e tratamento. A análise das trajetórias assistenciais sugere uma baixa efetividade da $\mathrm{AB}$, tanto na prevenção quanto no diagnóstico das DCNT, demonstrando a inexistência de linhas de cuidado.

> Key words: políticas públicas de saúde; avaliação em saúde; doenças crônicas.

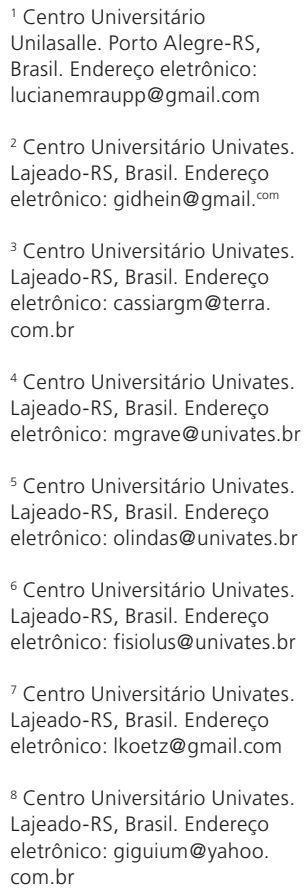

${ }^{1}$ Centro Universitário Unilasalle. Porto Alegre-RS, Brasil. Endereço eletrônico: lucianemraupp@gmail.com

${ }^{2}$ Centro Universitário Univates. Lajeado-RS, Brasil. Endereço eletrônico: gidhein@gmail.com

${ }^{3}$ Centro Universitário Univates. Lajeado-RS, Brasil. Endereço eletrônico: cassiargm@terra. com.br

${ }^{4}$ Centro Universitário Univates. Lajeado-RS, Brasil. Endereço eletrônico: mgrave@univates.br

${ }^{5}$ Centro Universitário Univates. Lajeado-RS, Brasil. Endereço eletrônico: olindas@univates.br

${ }^{6}$ Centro Universitário Univates. Lajeado-RS, Brasil. Endereço eletrônico: fisiolus@univates.br

${ }^{7}$ Centro Universitário Univates. Lajeado-RS, Brasil. Endereço eletrônico: Ikoetz@gmail.com

${ }^{8}$ Centro Universitário Univates. Lajeado-RS, Brasil. Endereço eletrônico: giguium@yahoo. com.br

\footnotetext{
* A pesquisa foi financiada pelo Edital FAPERGS/MS/CNPq/SESRS nº 002/2013.
} 
As doenças crônicas não transmissíveis (DCNT) corresponderam a 63\% dos óbitos mundiais em 2008, sendo que $80 \%$ destes ocorreram em países de baixa e média renda. No Brasil, as DCNT são responsáveis por $72 \%$ das causas de morte, sendo $31,3 \%$ por doenças cardiovasculares, $16,3 \%$ por câncer, $5,2 \%$ por Diabetes mellitus (DM) e 5,8\% por doenças respiratórias crônicas (BRASIL, 2011). Essa situação de saúde está relacionada à transição demográfica acelerada, ocasionada pela queda da fecundidade e pelo aumento da expectativa de vida, levando ao envelhecimento populacional, assim como à transição epidemiológica resultante da queda na mortalidade por condiçōes agudas, principalmente infecciosas. Fatores comportamentais e de estilo de vida como tabagismo, inatividade física, excesso de peso e uso excessivo de álcool e outras drogas também contribuem para a tendência de aumento das DCNT (MENDES, 2012).

Considerando esse contexto, a rede de atenção à saúde precisa adaptar-se à atual situação, reorganizando o cuidado à pessoa com doenças crônicas. De acordo com o Ministério da Saúde (BRASIL, 2013), as DCNT apresentam início gradual, com duração longa ou incerta, e, geralmente, múltiplas causas. Seu tratamento envolve mudanças de estilo de vida, em um processo de cuidado contínuo que não visa à cura, mas à estabilização da condição de saúde e ao incremento da qualidade de vida do usuário. Visando dar conta dessa reorganização do sistema de saúde, em 2013, foi lançada a Portaria no 252 do Ministério da Saúde, que institui a rede de atenção à saúde das pessoas com doenças crônicas, no âmbito do Sistema Único de Saúde (SUS).

Segundo essa normativa, a rede de atenção à saúde deve oferecer atenção de forma integral aos usuários com DCNT “[...] em todos os pontos de atenção, com realização de ações e serviços de promoção e proteção da saúde, prevenção de agravos, diagnóstico, tratamento, reabilitação, redução de danos e manutenção da saúde" (BRASIL, 2013). Para a concretização dessa proposta, fazse necessária uma reorganização do sistema de saúde com foco no usuário, com vistas a qualificar tanto o acesso quanto às práticas de acolhimento, articulação intersetorial, dinamização das formas de controle social e de concretização da equidade, entre outras ações, no sentido de qualificar o cuidado sem descuidar das práticas de promoção e prevenção. 
Para que a lacuna entre a teoria e a realidade do SUS não inviabilize ou despotencialize a concretização de uma rede de atenção integral a esse público, é fundamental a análise do cotidiano das pessoas com DCNT e dos itinerários que percorrem em busca de cuidados em saúde. Nesse sentido, investigações que considerem a perspectiva dos usuários e sua satisfação ou insatisfação com a atenção recebida são consideradas estratégicas por permitirem avaliar a atenção, com o intuito de influenciar o nível de qualidade dos serviços prestados (UCHIMURA; BOSI, 2002).

Canesqui (2013), por exemplo, assinala que é comum homens e mulheres desconfiarem de - e até mesmo ignorarem - diagnósticos de hipertensão arterial sistêmica, pois geralmente não há manifestações corporais. Por desconhecerem a enfermidade e suas consequências, deixam de tratá-las e controlá-las pelo uso de remédios e de outras medidas preventivas. Dessa forma, a descrição e a análise de trajetórias assistenciais trazem à tona a ótica do usuário sobre a efetividade e a qualidade da atenção à saúde. São ainda incipientes no Brasil investigações com a finalidade de compreender como e em que momento pessoas buscam ajuda para resolver demandas e problemas de saúde. No entanto, tais pesquisas têm um potencial promissor para subsidiar processos de organização de serviços de saúde e gestão, em prol da construção de práticas assistenciais compreensivas e contextualmente integradas (CABRAL et al., 2011).

Diante do exposto, este estudo teve como objetivo destacar a ótica dos usuários do SUS a partir da descrição e análise das trajetórias assistenciais de pessoas com condiçôes crônicas mais prevalentes, residentes nos municípios da 16a Coordenadoria Regional de Saúde do Rio Grande do Sul (16 CRS/RS). A análise das DCNT nessa região foi efetivada na parte quantitativa do estudo que não será apresentada neste artigo - e orientou a seleção dos usuários a serem entrevistados na parte qualitativa, foco desta produção.

\section{Procedimentos metodológicos}

O estudo visou conhecer as trajetórias assistenciais de pessoas acometidas por condições crônicas na sua experiência de adoecimento, sob a sua ótica. Foram incluídos no estudo indivíduos entre 20 e 74 anos de idade, residentes em municípios da 16a CRS. A pesquisa seguiu os preceitos éticos da Resolução no 
466/13 do Conselho Nacional de Saúde sobre pesquisa com seres humanos, tendo sido aprovada pelo Comitê de Ética em Pesquisa do Centro Universitário Univates, sob protocolo 107.219, de 22 de outubro de 2012.

$\mathrm{Na}$ época de elaboração deste estudo, a área da $16^{\mathrm{a}} \mathrm{CRS}$ era composta por 42 municípios, dentre os quais 59,5\% ( $\mathrm{n}=25)$ eram considerados pequenos, com população em torno de 3 a 4 mil habitantes. Isso implica reconhecer a peculiaridade dessa região, que conta com pequenos municípios distribuídos em uma área geográfica limitada, dependentes de outras cidades, que possuem uma rede assistencial de saúde de média complexidade. A maior cidade da região tem aproximadamente 72 mil habitantes.

Os critérios para seleção dos municípios foram: dois municípios com 100\% de cobertura da ESF, dois com cobertura parcial e dois sem cobertura. Em cada um dos grupos, foram selecionados um município com população superior e outro com população inferior a 10.000 habitantes. Em cada município, foi selecionada uma pessoa com cada uma das duas DCNT mais prevalentes (doenças cardiovasculares e neoplasias), totalizando 12 sujeitos. Os participantes foram selecionados aleatoriamente, através do sorteio de prontuários de usuários dos serviços de $\mathrm{AB}$ dos municípios. As entrevistas foram realizadas na residência dos participantes, após contato telefônico, e posteriormente gravadas e transcritas. Para garantir a confidencialidade da identidade dos sujeitos, os nomes citados ao longo do texto foram alterados por pseudônimos.

As trajetórias assistenciais foram reveladas por meio da descrição e análise das entrevistas. Durante esse procedimento, foram identificadas unidades de significação, que delinearam a constituição de categorias. As interpretações foram realizadas através do método de Análise de Conteúdo (BARDIN, 2012). $\mathrm{Na}$ categoria "Acesso ao sistema de saúde", foram abordados temas relativos às formas de entrada dos usuários no sistema de saúde (porta de entrada no sistema). As dificuldades de acesso para a obtenção de atenção em saúde, bem como acesso a transporte, urgência e medicaçōes também foram abordadas nessa categoria. Dados relacionados à percepção da atenção prestada na atenção básica $(\mathrm{AB})$, à avaliação da atenção recebida e ao tempo entre diagnóstico e tratamento foram contemplados na categoria "A satisfação dos usuários com os serviços de saúde". 


\section{Acesso ao sistema de saúde}

Dos 12 usuários entrevistados, sete realizaram todos os atendimentos e procedimentos necessários pelo SUS. Destes, quatro iniciaram o tratamento das DCNT nas equipes de $\mathrm{AB}$, recebendo posteriormente os encaminhamentos para consultas com especialistas e de exames na atenção secundária do seu ou de outros municípios, como no exemplo abaixo:

Bom eu senti assim, me tocando, tomando banho [...]. Aí estava assim: faltava um mês para eu fazer minha consulta com ele (clínico geral da UBS), pois eu uso DIU e faço revisão de seis em seis meses. Aí eu falei quando achei o nódulo: 'Olha, eu achei um nódulo'. Ele disse: 'Deixa eu te examinar', e disse: 'O nódulo tá aí, vamos ver o que tem dentro'. Aí eu fui então fazer a mamografia, aí já constou [...]. Tudo pelo posto. O doutor de lá me deu os papéis e eu fui daí para o hospital (Maria).

Desses casos, apenas um usuário relatou que a Agente Comunitária de Saúde (ACS), em uma das visitas de rotina à sua residência, percebeu seu mal estar e marcou consulta com a médica da Unidade Básica de Saúde (UBS). A consulta resultou no diagnóstico de câncer de próstata a partir da realização de exame de toque. $\mathrm{O}$ usuário foi então encaminhado para um especialista no hospital de referência regional.

Um dado que se destacou nas entrevistas foi a pouca menção à figura dos ACS, citados apenas mediante questionamento por parte dos entrevistadores.

Entrevistadora: A agente de saúde vem aqui na casa de vocês?

José: Vem, ela vem, foi ela que encaminhou a consulta. Daí fiz exame de próstata, daí apareceu o câncer e daí depois me encaminharam, e todo mês tinha que ir ao médico, daí o posto marcava pro médico do hospital. E daí eles marcavam e eu ia.

Ainda em relação à $\mathrm{AB}$ como porta de entrada para o sistema de saúde, mesmo entre usuários que a acessavam ou moravam em locais cobertos por equipes de Estratégia de Saúde da Família (ESF), a busca por atenção nas UBS ocorria, em geral, apenas quando os sintomas das DCNT apareciam. Segundo Teixeira Júnior (2010), embora a proposta da ESF seja embasada na ideia de aproximar a equipe de saúde da comunidade pertencente ao território onde atua, isso não é uma garantia de que os serviços sejam acessados de forma plena. De acordo com o autor, o acesso não se define apenas pela entrada nos serviços, mas abrange fatores que influenciam o uso e a efetividade do cuidado. Essa busca tardia por 
cuidados se fez presente no caso de Osmar, que recebeu o diagnóstico de câncer de próstata apenas quando já era inviável fazer cirurgia de remoção da região afetada. Seu caso é semelhante ao de Dulce, que também descobriu ter câncer quando já apresentava várias metástases:

Entrevistadora: E tu já eras acompanhado antes aqui pelo posto?

Osmar: Não, não tinha sido. Agora eu sou [...]. Só que agora não dá mais para operar, o câncer tá muito avançado e tou muito fraco. Por isso é que tão dando essa injeção, pra controlar.

Entrevistadora: E tu não fazias exames antes?

Osmar: Não, nada. Mas daí depois que comecei a ficar ruim, fui ao médico e mandaram fazer esses exames e apareceu isso.

Tinha posto lá de saúde lá, mas a gente não foi procura. Sei lá é um relaxo da gente, né $[\ldots]$ (Dulce).

Esse comportamento de buscar atenção apenas quando os sintomas aparecem ou quando ocorre uma crise prevaleceu entre os usuários entrevistados, conforme exposto na fala de Eduardo, que já havia sofrido quatro episódios de acidente vascular encefálico. Em todos esses eventos, dirigia-se ao pronto atendimento de seu município sem dar continuidade ao tratamento em outros pontos da rede: “[...] só procura quando tá no fim” (Eduardo). A grande maioria dos usuários entrevistados não referia participar de atividades de promoção ou prevenção em saúde. Procuravam locais com pronto atendimento em casos agudos e tinham pouco contato com as UBS, que não frequentavam, ou as procuravam apenas para consultas ou procedimentos eventuais, antes de terem conhecimentos de suas DCNT.

Assim, na maioria dos casos, o comportamento de busca de cuidados em saúde demonstrou a existência de linhas de cuidado invertidas (CECCIM, 2007). A busca de cuidados em saúde, na região estudada, ocorre em momentos de crise, quando o usuário recorre a serviços de média complexidade, usufruindo com mais frequência da atenção primária posteriormente para o tratamento da DCNT.

As linhas de cuidado invertidas foram referidas em um estudo sobre itinerários terapêuticos de usuários da assistência suplementar em saúde, de forma semelhante ao presente estudo. A participação em ações de promoção da saúde entre os usuários pesquisados ocorria apenas quando as doenças já estavam instaladas de forma severa (CECCIM, 2007). Segundo o autor, os usuários 
pesquisados tendiam a supervalorizar os procedimentos tecnológicos da atenção

secundária e terciária em situação de risco de vida, sem fazer menção aos recursos de outros níveis de cuidado.

No caso de Eduardo, com problemas de hipertensão arterial sistêmica (HAS) há anos, a busca pelo pronto atendimento do hospital de referência regional era a única opção acessada para lidar com seu problema de saúde. Voltava para casa após a melhora dos sintomas e tomava as medicaçōes prescritas até o próximo episódio de crise, constituindo assim um ciclo de idas e vindas ao pronto atendimento:

Chamou a SAMU, e eles vieram logo. Me atiraram lá dentro do carro e me levaram pro hospital. Eu fiquei dois dias em [nome da cidade onde há o hospital de referência regional], e fiquei bom; bom não, né, aí quando foi sábado passado, de novo. [...] Estava na igreja e comecei a passar mal; aí eu caí e ela [amiga] me segurou, me botaram no carro e quanto eu vi não era nem 11 horas eu já estava lá no pronto-socorro de novo. [...] Então, quando eu não morava aqui eu ia pro Centro, ia direto pra [nome da cidade onde há o hospital de referência regional], quando estava ruim assim (Eduardo).

Mais recentemente, Eduardo mudou-se para um município onde há uma UBS, e seus cuidados, como fisioterapia, por exemplo, passaram a ser ali realizados. No entanto, demonstra estar ainda vinculado ao hospital de referência regional, utilizando os cuidados da UBS apenas para necessidades pontuais.

Agora eu estou vindo aqui [UBS] porque eu moro nesse município e me mandaram trocar tudo pra cá [...]. Olha o que eu estou fazendo, por enquanto, é a fisioterapia porque eu tenho problema nos nervos, umas coisas esquisitas, mas as consultas eu tenho sempre feito lá fora. Uma vez consultei com o médico daqui do posto, mas faz tempo, foi ainda no ano passado, nem lembro o nome dele (Eduardo).

Cinco usuários mesclaram a busca por serviços públicos e privados do sistema de saúde. Os usuários pagaram com recursos próprios ou utilizaram planos de saúde para consultas com médicos especialistas e exames, quando considerados de urgência. Os planos de saúde, na maioria dos casos, eram disponibilizados pelas empresas nas quais trabalhavam.

Destes, três usuários utilizaram como porta de entrada no sistema de saúde o pronto atendimento do hospital de seu município ou do município mais próximo. Uma usuária consultou diretamente um especialista e foi encaminhada, a partir de então, pelo SUS, para a realização de procedimentos em serviços de média complexidade. A dificuldade de acesso mais alegada como motivo para pagar pelos 
atendimentos foi o desejo ou a necessidade de ter acesso rápido à consulta desejada, evitando assim o tempo de espera no SUS. Esse motivo pode ser percebido na fala de Dulce, que foi encaminhada para um oncologista após ter recebido um atendimento de urgência no pronto atendimento do hospital de sua cidade:

Já que o médico me encaminhou para um especialista, a gente sabe que não é uma coisa bem simples, né? Eu acho assim. Daí eu falei com a secretária dele e disse: Se eu pagar, quando que eu posso ter a consulta? Já pode ser amanhã? Daí eu paguei (Dulce).

Outra usuária se referiu ao tempo gasto para marcar consultas via SUS como o problema que tentava evitar ao pagar consultas particulares:

É meio demorado. Tem que passar pelo clínico geral, e daí tu já perde aquela manhã toda, manhã ou tarde, perde no posto de saúde. Daí prefiro pagar e ter logo a consulta (Ana).

Também em relação ao pronto atendimento, a demora por consultas foi referida por alguns como uma grande dificuldade de acesso à atenção necessária. No caso a seguir, a usuária relata que, frente ao que compreendeu como um descaso na atenção aos usuários que esperavam por atendimento, optou por pagar a consulta, obtendo a partir de então um atendimento bastante rápido:

Eu tava lá com dor e tinha um lendo jornal, outro estava caminhando. Ali tinha umas cento e cinquenta pessoas desde antes de meio dia acho, e já eram nove ou dez horas da noite. Daí uma mulher me viu e disse: 'Tu tá ainda ali sentada? Tu tá toda branca, mulher!' Daí eu pedi: 'Será que não chegou a minha vez ainda?' Não. Daí eu fui procurar o doutor [nome do médico] e disse que preferia então pagar, mas não ficar ali sofrendo. Aí eles ligaram pra ele e em meia hora ele estava ali, daí não demorou nem dez minutos (Dulce).

Essa diferença entre os tempos de atendimento público e privado já é algo institucionalizado no país, conforme referido por Santos e colaboradores (2008). Os autores afirmam que o segmento de planos e seguros de saúde diferencia-se principalmente devido aos serviços de hotelaria oferecidos, à maior facilidade para agendar atendimentos, e à maior possibilidade de escolher medicamentos não genéricos. Esse último fato foi referido por Paulo, residente em uma área com cobertura de ESF:

Fiz a consulta pelo plano de saúde e o médico disse: 'A partir de hoje vamos investir no senhor, na sua saúde; não quero que o senhor tome mais nenhum remédio do SUS para pressão'. Proibiu. Daí eu disse: 'tá bom'. Aí eu comecei a tomar, eu compro até hoje o remédio (Paulo). 
Ainda no tocante aos usuários que buscaram atendimentos particulares quando sentiram os primeiros sinais/sintomas de suas enfermidades, ou após a consulta no pronto atendimento, destacou-se a importância creditada à figura do médico especialista em detrimento do papel tributado ao clínico geral e à $\mathrm{AB}$ como um todo, como referido na fala de Emerson:

Entrevistadora: $\mathrm{O}$ senhor consulta aqui na UBS? Tem algum agente de saúde que vai à sua casa?

Emerson: É, vai o agente de saúde sempre, mas raramente eu consulto aqui. A maioria das vezes eu consulto com meu cardiologista em [outro município].

$\mathrm{A} A \mathrm{~B}$ é acessada, nos casos pesquisados, para a realização de procedimentos pós-cirúrgicos, como curativos, por exemplo, ou para o agendamento de consultas na média complexidade. Mesmo a AB se caracterizando pela grande proximidade com o cotidiano da vida das pessoas e coletivos em seus territórios, ela ainda está longe de atingir seu objetivo. A AB deve ser mais do que a "porta de entrada" ao sistema de saúde: deve ser uma "'porta aberta”, capaz de dar respostas 'positivas' aos usuários, não podendo se tornar simplesmente um lugar burocrático e obrigatório de passagem para outros tipos de serviço (BRASIL, 2006, p. 14).

Sim, até vou ao posto, mas isso depende do caso. Se for um caso mais grave a gente vai ao pronto atendimento. Mas quando eu precisava fazer curativos, depois da cirurgia, ia todo dia lá (Dulce).

Fui num [médico] particular porque se tu vai num posto de saúde, é meio demorado. Aí tu tem que passar pelo clínico geral, e daí tu já perde aquela manhã toda lá. Tá, daí às vezes acontece de chegar e ser logo atendida, mas geralmente tu perde a manhã ou a tarde. E aí tem que pedir encaminhamento; igual nós não temos, que eu saiba, cardiologista aqui pelo SUS, acho que até tem, mas aí demora, capaz de levar uns dois ou três meses. [...] Eu acho que, em vista de outros municípios que eu vejo reclamarem, claro que não tem aqui, mas precisava de uns médicos melhores, como é que vou dizer [...], precisava de um cardiologista (Vera).

Percebe-se por esses relatos o reflexo de uma concepção arraigada na história da relação dos brasileiros com o sistema público de saúde. A AB é associada a uma atenção simplificada e de baixo custo, efetivada através de serviços simples e poucos equipamentos, ou seja, vista como um tipo de medicina simplificada. $\mathrm{Na}$ realidade, essa concepção se opõe à proposta de prática do cuidado atual nesse nível de atenção, dado ser a $A B$ a dimensão orientadora da reorganização assistencial no país. Nesse papel, a AB compõe uma tecnologia de atenção ligada a práticas na maioria das vezes complexas, 
nas quais à realização de procedimentos e prestação de serviços tradicionais em saúde soma-se o conhecimento oriundo da presença do território onde atua, visando à longitudinalidade na atenção prestada (ROCHA, 2012).

Em relação ao acesso a transporte em casos de emergência ou de necessidade de ida a outra cidade para atendimentos, consultas ou exames, alguns usuários referiram preferir se deslocar com transporte próprio (levados por algum familiar), mas todos relataram terem à disposição transporte do município de origem:

Sim, sim. Eu vou, eu ligo para o posto, eles me levam e me buscam. Todo meu tratamento eles me levaram, me buscaram, fizeram os curativos, foi tudo, não posso me queixar, tudo eu fiz pelo SUS (Paulo).

Em pesquisa realizada por Dubeux, Freese e Felisberto (2013), em Pernambuco, com 853 entrevistados, com o objetivo de identificar possíveis problemas no itinerário e na assistência prestada no hospital, os pontos mais evidenciados pelos usuários foram a necessidade de pagar transporte para chegar ao hospital (53,7\%), necessidade de comprar remédios $(55,3 \%)$ e necessidade de pagar para fazer exames complementares $(52,4 \%)$. Esses itens também foram relatados pelos entrevistados na pesquisa deste artigo, que apontaram, no entanto, que o transporte é disponibilizado pelos municípios.

Quanto ao acesso a medicamentos, todos os usuários recebiam tudo ou parte do que necessitavam via UBS.

Recebo porque eu tomo pra pressão alta, aí tenho esse cardiologista, que me receita pra pressão, aí eu tenho um outro que tomo, tranquilizante, que é o médico do posto. O da depressão eu tenho que comprar, só o que eu compro é esse, mas o resto eu ganho tudo (Ana).

A discussão realizada até o momento mostra o acesso aos diferentes serviços e cuidados oferecidos na região da 16 a CRS/RS, que é efetivado de diferentes formas, mesclando o público e o privado. A seguir, apresentaremos a análise da satisfação dos usuários com os serviços acessados.

\section{A satisfação dos usuários com os serviços de saúde}

Estudos sobre satisfação de usuários em serviços de saúde ganharam destaque, nos Estados Unidos e na Inglaterra, principalmente na década de 1970, a partir de uma proposta do consumismo e da cultura da qualidade. Dessa forma, a satisfação do 
usuário passou a ser meta a ser alcançada pelos serviços. No Brasil, os estudos se desenvolveram na década de 1990, “a partir do fortalecimento do controle social no âmbito do SUS, por intermédio da participação da comunidade nos processos de planejamento e avaliação" (ESPERIDIÃO; TRAD, 2006, p. 1268).

Os serviços de saúde podem ser avaliados partindo-se de diferentes perspectivas e expectativas que determinarão os rumos da avaliação. Cada usuário, enquanto sujeito da avaliação, parte de seus próprios valores e expectativas relativas ao serviço. Considerar a satisfação dos usuários como indicador de qualidade dos serviços de saúde é uma forma de incorporar a perspectiva do usuário nos processos de avaliação. Segundo Cotta e colaboradores (2008), engajar os usuários do SUS no processo de entendimento de sua problemática de saúde, nas discussões de suas soluções possíveis e no acompanhamento da implementação e avaliação de programas a eles destinados colabora para o processo de empoderamento e libertação da população, em favor da melhoria da qualidade de vida.

A avaliação e a satisfação do usuário como protagonista do sistema de saúde têm impacto direto na melhoria do serviço. Assim, é fundamental conhecer como os usuários avaliam o atendimento prestado, para repensar as práticas profissionais ou intervir sobre a forma de organização dos serviços, visando seu aperfeiçoamento (DIAS et al., 2010).

Segundo Vaitsman e colaboradores (2003), as percepções não se desenvolvem apenas baseadas na experiência imediata das pessoas, mas como parte de um conjunto de representações e valores pré-existentes sobre o mundo social, incluindo as hierarquias e as relações de poder na sociedade, que se reproduzem também nas relações que ocorrem nas organizações. Nesse sentido, considerando o modo como as organizações públicas de saúde e as relações entre Estado e sociedade foram sendo instituídas, as relações do sujeito com a coisa pública precisam ser consideradas.

A satisfação dos usuários deve ser avaliada, portanto, a partir de um conjunto de fatores que inclua: as condições de acesso; a capacidade de resolução da situação que gerou a demanda; o próprio atendimento, ou seja, o acolhimento; o profissional de saúde e a forma como presta o atendimento; e as condições do ambiente onde é realizado o atendimento, tais como limpeza, organização e conforto das instalações, as condições do prédio e dos equipamentos (STENZEL; OLIVEIRA, 2004). 
Esperidião e Trad (2006) ressaltam a importância de o usuário estar satisfeito com o atendimento recebido na aderência ao tratamento, na busca por informaçōes sobre sua saúde/doença de forma mais eficaz e na continuação do uso dos serviços de saúde. Além disso, as autoras apontam que "usuários satisfeitos são mais propensos a ter melhor qualidade de vida" (p. 1268).

Conforme estudo realizado por Dubeux, Freese e Felisberto (2013), já mencionado acima, "entre os critérios para avaliação dos itinerários até os hospitais regionais, foram identificadas diversas razōes para o entrevistado selecionar a unidade estudada. Ressaltam-se, entre elas, a confiança/credibilidade depositada pelo usuário na assistência prestada no hospital $(39,0 \%)$ e a proximidade entre sua residência e o serviço (15,8\% dos motivos elencados)" (p. 354).

Dessa forma, nas entrevistas realizadas em nosso estudo, nenhum usuário apontou demora no recebimento do tratamento indicado após o diagnóstico de sua enfermidade. Todos avaliaram que a atenção prestada foi rápida e eficiente. Quanto ao tempo entre diagnóstico, terapêuticas e cirurgias - dois usuários referiram complicações cirúrgicas - houve variação de um a seis meses. Os casos nos quais a demora foi superior a três meses envolveram o tempo necessário para a realização de quimioterapias e radioterapias, que ocorreram no hospital de referência regional. Apenas uma usuária referiu ter acessado o hospital de referência estadual para realizar cirurgia cardíaca, devido à falta de vagas em hospitais mais próximos de seu município:

Passei mal, daí fui a [cidade], fiz uns exames, e de lá o médico me encaminhou para Porto Alegre. Aí, chegando em Porto Alegre, tive que ficar para fazer cateterismo, isso foi numa segunda, e voltei só no sábado (Rita)

No tocante à avaliação dos diversos pontos da rede de atenção, independentemente do acesso ter sido ou não totalmente pelo SUS, todas as respostas foram positivas quanto à atenção recebida:

Não digo que não precisa melhorar, que vocês sabem que precisa melhorar muita coisa, mas eles me atenderam otimamente tanto aqui quanto lá embaixo (Paulo).

Ótimo! Ótimo. O atendimento em [cidade] não sei se todo o setor é igual, mas no setor que eu tava os médicos são um melhor que o outro. Fiquei na UTI, bom, eu não tenho nada que pensar de coisa ruim que passei lá, e olha que eu fiquei onze dias. Muito bom. A comida, se tu não gosta de uma fruta, eles pedem se tu queres outra (Joana).

As únicas queixas ouvidas foram em relação ao acesso e à qualidade da recepção aos usuários no pronto atendimento de um hospital da região. Mesmo 
não sendo referência regional, quando não há vagas nas emergências de referência (municipais), os usuários buscam atendimento nesse local:

Eu sempre fui bem atendida lá, nota dez [hospital de referência regional]. Mas no hospital de [nome do município] não é tanto, a emergência não é muito boa (Maria).

Nos últimos anos, vem sendo observada, seguindo uma tendência mundial, a criação de ouvidorias em hospitais públicos e privados, que funcionam como canais de comunicação e democratização das relações entre os serviços e os seus usuários. No entanto, acredita-se que as organizações públicas ainda precisam avançar na capacidade de dar respostas às queixas e denúncias encaminhadas pelos usuários (STENZEL; OLIVEIRA, 2004).

Ferri e colaboradores (2007) afirmam que as práticas de atenção ainda se voltam para atender doenças e centram-se no modelo queixa-conduta, onde o saber biológico e intervenções técnicas e medicalizantes são recorrentes. Essas condutas são fruto de um longo período histórico, "que tem suas raízes no conjunto de dicotomias que atravessa a organização dos serviços de saúde e que vem sendo sustentada pela lógica de mercado, com a finalidade de obtenção de lucro, ficando as necessidades de saúde da população num plano secundário" (p. 517).

Ressaltamos que não estamos negando a importância do saber biológico, mas a preocupação em não tomar essa ideia como única e unilateral, mas pensar o usuário na sua singularidade, levando em conta suas questões emocionais, culturais e sociais. Assim, Ferri e colaboradores (2007) destacam a necessidade de tomarmos a produção do cuidado como "a finalidade do processo de trabalho em saúde” (p. 517). Em nossa pesquisa, nas falas evidenciadas, foram pontuadas como positivas justamente as ações de cuidado que levavam em conta aspectos relacionais.

Eu gosto, gosto do pessoal do posto. Não tenho queixa de ninguém aí, e quando precisa e quando não tenho como ir até lá, e só ligar pra que eles vem aqui. É, eu não posso me queixar (Joana).

Nesse sentido, Merhy e Feuerwerker (2009) apontam as tecnologias leves como instrumentos necessários no cotidiano da produção dos serviços de saúde. Estas são definidas como a produção de cuidado focada nas relações envolvidas no encontro trabalhador-usuário mediante a escuta, o interesse e a construção de vínculos e de confiança. Segundo os autores, essa forma de "trabalho vivo em ato" (p. 6) possibilita captar a singularidade, o contexto cultural e os modos de 
andar a vida dos usuários, tornando mais efetiva, inclusive, a aplicação de outros tipos de tecnologias também necessárias na prática do cuidado em saúde, como as tecnologias duras, nas quais o foco é a produção de procedimentos.

A Política de Humanização da Atenção e da Gestão (PNH), do Ministério da Saúde, criada em 2003, tem por objetivo qualificar práticas de gestão e atenção em saúde. Na perspectiva da humanização essa política corresponde à produção de novas atitudes por parte de trabalhadores, gestores e usuários, de novas éticas no campo do trabalho, incluindo aí o campo da gestão e das práticas de saúde, superando problemas e desafios do cotidiano do trabalho (BRASIL, 2010).

Investigações com foco nas trajetórias assistenciais dos usuários são capazes de mostrar as potencialidades e dificuldades existentes. Estudos qualitativos voltados à investigação da organização e da capacidade da rede de atenção à saúde em responder às necessidades de pessoas com doenças crônicas ainda são escassos (MEDEIROS, 2013). Talvez resida aí uma convocação aos pesquisadores para ampliarem seus campos de pesquisa e investirem em trabalhos no âmbito qualitativo das produções.

Campos (2007) ressalta, ainda, que o avanço e a consolidação das diretrizes da reforma sanitária brasileira dependem, entre outros fatores, do aprimoramento dos mecanismos de controle social, admitindo a importância estratégica das pressões sociais para o aprimoramento do sistema. Assim, estudos que abordam o ponto de vista dos usuários sobre a atenção recebida nos diversos pontos da rede de saúde são dispositivos importantes para visibilizar o cotidiano dos usuários do SUS.

\section{Considerações finais}

Os relatos dos 12 usuários entrevistados mostram que o tratamento e o acompanhamento das DCNT ocorreram predominantemente no SUS. Os cinco usuários que referiram utilizar a atenção privada para consultas com médicos especialistas ou para acessar mais rapidamente o pronto atendimento - via plano de saúde ou pagamento privado - buscavam superar as desigualdades na atenção às suas necessidades. Compreende-se isso como uma expressão das dificuldades dos pequenos municípios em suprir todas as necessidades de saúde da população (MEDEIROS, 2013). Além disso, a ampla utilização de serviços públicos e privados na atenção à saúde revela o quanto, de uma forma geral, o SUS ainda não conseguiu garantir a universalidade de acesso, com o setor 
de saúde suplementar ocupando um papel importante na oferta e prestação de serviços no país (CECCIM, 2007).

Os dados provenientes dos municípios estudados refletem o perfil da atenção na $16^{a} \mathrm{CRS} / \mathrm{RS}$, onde predominam pequenos municípios, que se mostraram capazes de mobilizar estratégias de tratamento das DCNT. Para tanto, valeram-se amplamente de recursos complementares em municípios vizinhos, demonstrando, assim, a importância das redes regionalizadas como estratégia de aperfeiçoamento institucional, gerencial e organizativo do SUS, conforme proposições do Ministério da Saúde (BRASIL, 2009).

As trajetórias descritas denotam, ainda, a necessidade de reavaliar, junto com os gestores, equipes de saúde e o controle social, a forma como estão organizadas as ações da $\mathrm{AB}$, bem como quais mudanças precisam ser implementadas para responder às necessidades dos usuários, considerando a incidência das DCNT na região e em cada município, de forma específica. A falta de acesso às açōes de promoção à saúde, prevenção de doenças e aos cuidados necessários frente aos processos de adoecimento dificultam a prestação da atenção universal e integral no SUS.

Um fator preocupante foi a pouca menção dos entrevistados a ações de prevenção ou promoção de saúde nos municípios, de forma que, mesmo nos casos de usuários que já apresentavam sintomas e complicações - oriundas, por exemplo, de HAS -, não eram efetivados acompanhamentos sistemáticos por parte das equipes de algumas UBS. Nesses casos, as trajetórias terapêuticas resumiam-se a várias idas e vindas a pronto atendimentos até o agravamento dos problemas de saúde, demonstrando uma coordenação ineficaz entre os diferentes níveis do sistema. A procura pela UBS (com poucas exceçōes) ocorreu após as cirurgias realizadas, na busca por medicamentos e por marcação de consultas na média complexidade. Nesse sentido, cabe ressaltar que medidas precisam ser tomadas para ampliar o número e o alcance das atividades de promoção e prevenção em saúde, envolvendo a intersetorialidade, de uma forma realmente qualificada, capaz de possibilitar conquistas e melhorias efetivas das condições de vida (MARIN et al., 2007).

Diante do exposto, cabe questionar de que forma as UBS poderiam ser mais efetivas e capazes de aproximar ações preventivas, de promoção, curativas e reabilitadoras, efetivando a diretriz de integralidade na atenção e levando em consideração que nos casos de municípios pequenos seria mais viável articular 
ações e serviços com qualidade, efetividade e equidade. Também se faz importante indagar o que está faltando para a ampliação do papel das equipes de ESF, em especial, visando potencializar o trabalho dos ACS, os quais raramente foram mencionados nas entrevistas.

Pelos relatos dos usuários, percebe-se o quanto o modelo médico hegemônico, centrado no atendimento aos doentes (PAIM, 2001), faz-se ainda presente como fator preponderante na atenção proporcionada em diversos pontos do sistema. No entanto, ações de cuidado multidisciplinar, tais como atendimentos com fisioterapeutas, psicólogos e nutricionistas, foram citadas por usuários em recuperação de neoplasias (ocorridas nos hospitais de referência e não nos municípios dos usuários) ou que passaram a frequentar as UBS para acessar esses serviços.

Da mesma forma, não se desconsidera o papel das barreiras culturais de acesso na conformação das trajetórias de cada usuário pelo sistema de saúde. Nesse sentido, o individualismo e o imediatismo que pautam a contemporaneidade, juntamente à valorização do modelo médico e da importância das especialidades médicas, se fazem presentes de forma hegemônica, mesmo entre pessoas com baixo nível de escolaridade ${ }^{1}$.

Dar visibilidade às trajetórias assistenciais de usuários com DCNT residentes nos municípios da região estudada buscou descrever e analisar como a rede de atenção local produz respostas a esse desafio atual e quais lacunas necessitam ser ainda superadas. Outras investigações com foco na avaliação em saúde sob a ótica do usuário podem ampliar os subsídios gerados neste estudo. Com isso, pode-se contribuir para a elaboração de propostas de promoção da saúde com foco na problematização e proposição de modelos de atenção para a assistência às condições crônicas, capazes de qualificar o atendimento da rede de saúde local, principalmente no que se refere à efetividade da $\mathrm{AB}$ e de redes regionalizadas, dois eixos estratégicos do Ministério da Saúde para operacionalização do SUS. ${ }^{2}$

\section{Referências}

BARDIN, L. Análise de Conteúdo. São Paulo: Edições 70, 2012.

BRASIL. Ministério da Saúde. Secretaria de Atenção à Saúde. Departamento de Atenção Básica. Política Nacional de Atenção Básica. Brasília: Ministério da Saúde, 2006. 
Gestão do SUS. Redes de produção de saúde. Brasília: Ministério da Saúde, 2009.

Secretaria de Atenção à Saúde. Política Nacional de Humanização. Formação e intervenção. Brasília: Ministério da Saúde, 2010.

Plano de Ações Estratégicas para o Enfrentamento das Doenças Crônicas Não Transmissiveis (DCNT) no Brasil 2011 - 2022. Brasília: Ministério da Saúde, 2011. Disponível em: <http://portal.saude.gov.br/portal/arquivos/pdf/cartilha_ plano.pdf>. Acesso em: 01 abr. 2014.

. Portaria n 252, de 19 de fevereiro de 2013. Institui a Rede de Atenção à Saúde das Pessoas com Doenças Crônicas no âmbito do Sistema Único de Saúde (SUS). Brasília, DF: Ministério da Saúde, 2013.

CABRAL, A. L. L. V. et al. Itinerários terapêuticos: o estado da arte da produção científica no Brasil. Ciência \& Saúde Coletiva. Rio de Janeiro, v. 16, n. 11, p. 4433-4442, 2011.

CANESQUI, A. M. Estudo de caso sobre a experiência com a "pressão alta”. Physis: Revista de Saúde Coletiva. Rio de Janeiro, v. 23, n. 3, p. 903-924, 2013.

CAMPOS, G. W. de S. O SUS entre a tradição dos Sistemas Nacionais e o modo liberalprivado para organizar o cuidado à saúde. Ciência \& Saúde Coletiva. Rio de Janeiro, v. 12, supl., p. 1865-1874, 2007.

CECCIM, R. B. Itinerários terapêuticos: relação público-privado e arranjos tecnoassistenciais na utilização de serviços de saúde na região sul do Brasil. Relatório final do subprojeto 1: Relação público-privado e arranjos técnicos assistenciais na utilização de serviços de saúde: um estudo de itinerários terapêuticos na região sul. 2007. Disponível em: http://www.ans. gov.br/portal/upload/biblioteca/UFRGS_Itinerariossul.pdf. Acesso em: dez. 2012.

COTTA, R. M. M. et al. Reflexões sobre o conhecimento dos usuários no contexto do Programa de Saúde da Família: a lacuna entre o saber técnico e o popular. Physis: Revista de Saúde Coletiva. Rio de Janeiro, v. 18, n. 4, p. 745-766, 2008.

DIAS, O. V.; RAMOS, L. H.; COSTA, S. de M. Avaliação da Qualidade dos Serviços de Saúde na Perspectiva da Satisfação dos Usuários. Revista Pró-univerSUS, Vassouras, v. 1, n. 1, p. 11-26, 2010.

DUBEUX, L. S.; FREESE, E.; FELISBERTO, E. Acesso a Hospitais Regionais de Urgência e Emergência: abordagem aos usuários para avaliação do itinerário e dos obstáculos aos serviços de saúde. Physis Revista de Saúde Coletiva. Rio de Janeiro, v. 23, n. 2, p. 345-369, 2013.

ESPERIDIĀO, M. A.; TRAD, L. A. B. Avaliação de satisfação de usuários: considerações teórico-conceituais. Cad. Saúde Pública. Rio de Janeiro, v. 22, n. 6, p. 1267-1276, 2006. 
FERRAZ, L.; AERTS, D. R. G. C. O cotidiano de trabalho do agente comunitário de saúde do PSF em Porto Alegre. Ciência \& Saúde Coletiva. Rio de Janeiro, v. 10, n. 2, p. 347-355, 2005.

FERRI, S. M. N. et al. As tecnologias leves como geradoras de satisfação em usuários de uma unidade de saúde da família. Interface - Comunic, Saúde, Educ. Botucatu, v. 11, n. 23, p. 515-29, 2007.

MARIN, M. J. S. et al. As contribuições da comunidade para o trabalho da equipe de um PSF. Revista Latino-Americana de Enfermagem. Ribeirão Preto, v. 15, n. 6, p. 1065-1071, 2007.

MEDEIROS, C. G. M. Redes de atenção em saúde: o dilema dos pequenos municípios. 2013. 201p. Tese (Doutorado em Enfermagem). Universidade Federal do Rio Grande do Sul, Rio Grande do Sul, 2013.

MENDES, E. V. O cuidado das condiçôes crônicas na atenção primária à saúde: o imperativo da consolidação da estratégia da saúde da família. Brasília: Organização Pan-Americana da Saúde, 2012.

MERHY, E.E.; FEUERWERKER, L.C.M. Novo olhar sobre as tecnologias de saúde: uma necessidade contemporânea. In: MANDARINO, A.C.S.; GOMBERG, E. (Org.). Leituras de novas tecnologias e saúde. São Cristóvão: EdUFS, 2009. p. 29-74.

PAIM, J. S. Saúde da família: espaço de reflexão e de contra-hegemonia. Interface-Comunic, Saúde, Educ. Botucatu, v. 5, n. 9, p. 143-146, 2001.

ROCHA, J. S. Y. Manual de Saúde Pública e Saúde Coletiva no Brasil. São Paulo: Atheneu, 2012. SANTOS, I. S.; UGÁ, M. A. D.; PORTO, S. M. P. O mix público-privado no Sistema de Saúde Brasileiro: financiamento, oferta e utilização de serviços de saúde. Ciência \& Saúde Coletiva. Rio de Janeiro, v. 13, n. 5, p. 1431-1440, 2008.

SILVA-JUNIOR, J. B. As doenças transmissíveis no Brasil: tendências e novos desafios pra o Sistema Único de Saúde. Ministério da Saúde. Saúde Brasil 2008: 20 anos de Sistema Único de Saúde (SUS). Brasília: Ministério da Saúde, 2009.

STENZEL, A. C. B.; OLIVEIRA, A. I. de. Satisfação dos usuários dos serviços públicos de saúde. In: MISOCZKY, M. C.; BORDIN, R. (Org.). Gestão local em saúde: práticas e reflexões. Porto Alegre: Dacasa, 2004. p. 87-102.

UCHIMURA, K. Y.; BOSI, M. L. M. Qualidade e subjetividade na avaliação de programas e serviços em saúde. Cad. Saúde Pública. Rio de Janeiro, v. 18, n. 6, p. 1561-1569, 2002.

VAITSMAN, J. et al. Metodologia de elaboração do índice de percepções organizacionais. Cad. Saúde Pública. Rio de Janeiro, v. 19, n. 6, p. 1-18, 2003. 
${ }^{1}$ Com exceção de uma usuária, os demais participantes das entrevistas possuíam ensino fundamental incompleto.

${ }^{2}$ G. Dhein participou da concepção do projeto, análise e interpretação dos dados e da aprovação da versão final a ser publicada. L. M. Raupp participou da concepção do projeto, análise e interpretação dos dados e da aprovação da versão final a ser publicada. O.M.F.L. Saldanha participou da concepção do projeto e da redação do manuscrito. M.T.Q. Grave participou da concepção do projeto, análise e interpretação dos dados e da aprovação da versão final a ser publicada. C.R.G. Medeiros participou da concepção do projeto, da análise dos dados e da aprovação da versão final a ser publicada. L.C.E. Koetz participou da concepção do projeto e da aprovação da versão final a ser publicada. G. Almerom participou da interpretação dos dados e redação do manuscrito. M.V. dos Santos participou da redação e da aprovação da versão final a ser publicada. 


\section{Chronic diseases and the history of care: evaluation of the health system in small municipalities}

This work presents the results of a qualitative analysis of a study that aimed at identifying and evaluating the care given to the most prevalent chronic conditions in the region covered by the 16th Regional Health Office. Semistructured interviews were made with 12 people who had Non-Transmissible Chronic Diseases (NTCD) describing their history of care. Basic care (BC) services of six municipalities were contacted. Participants were selected according to criteria of population and coverage of the Family Health Strategy (ESF). Interviews were analyzed using the Content Analysis method in the following categories: Access to the Health System where topics regarding the ways in which users enter the health system and their health care histories were discussed. The difficulties of access to obtain health care, access to public transportation systems, urgency and medications were also discussed. Data involving perception of the care provided in $\mathrm{BC}$, the evaluation of the care received and the time elapsed between diagnosis and treatment were considered in category A, user satisfaction with the health services. The analysis of health care histories suggests low efficacy of the BCs, both for prevention and diagnosis of the NTCDs, showing that there are no lines of care.

> Palavras-chave: public health policies; evaluation in health; chronic diseases. 